\title{
The Intentionality of Sensation and the Problem of Classification of Philosophical Sciences in Brentano's empirical Psychology
}

\author{
Ion Tănăsescu ${ }^{1}$
}

\begin{abstract}
In the well-known intentionality quote of his Psychology from an Empirical Standpoint, Brentano characterises the mental phenomena through the following features: (i) the intentional inexistence of an object, (ii) the relation to a content, and (iii) the direction toward an object. The text argues that this characterisation is not general because the direction toward an object does not apply to the mental phenomena of sensation. The second part of the paper analyses the consequences that ensue from here for the Brentanian classification of mental phenomena: in Brentano's psychology one can distinguish two concepts of mental phenomena - the mental phenomenon in a broad sense and the mental phenomenon in a narrow sense; the former concept allows the separation of the mental from the physical, while the narrow concept allows the distinguishing of the main classes of mental phenomena. The third part of the paper shows that, with respect to sensation, the absence of a direction toward an object is compatible with both Brentano's early taxonomies of philosophical sciences, and his early program for the establishment of a new, empirical and non-speculative philosophy. For this reason, I hold that intentionality is important for the foundation of both psychology, and empirical philosophy.
\end{abstract}

Keywords Empirical psychology Empirical philosophy Classification of sciences Mental act Intentionality Sensation

One of the main criticisms addressed by Husserl to Brentano in his "Appendix" to the Logical Investigations, is that Brentano considers the sensations as mental [244] phenomena (LI, II, $348,358) .{ }^{2}$ For Husserl, however, the sensations are not mental acts, but sensory contents of consciousness (LI, II, 85, 348, 358). Although these contents are present in consciousness as evidently as the mental acts, they are not intentional experiences because they lack the generic determination of these experiences (LI, II, 96 f., 101). Specifically they lack the property of being intentions, i.e., of being directed toward an object that is not given in the

\footnotetext{
${ }^{1}$ Institute of Philosophy of the Romanian Academy, Romanian Academy, Calea 13 Septembrie 13,050711 Bucharest, Romania; iontanasescu964@gmail.com This is the extended version of the accepted manuscript of the paper published in Axiomathes (2017) 27: 243-263. The new additions are inserted in brackets. The final publication is available at link.springer.com.https://link.springer.com/article/10.1007\%2Fs10516-016-9300-8
}

${ }^{2}$ For the sake of fluency, the following abbreviations will be used: PES for Psychology From an Empirical Standpoint (1995a), DP for Descriptive Psychology (1995b) and LI for Logical Investigations (2001). In this article I analyse further the problem of intentionality of sensation, which I addressed the last time in Tănăsescu 2013. That article underlies the present paper. 
unity of consciousness, but is transcendent to it (LI, II, 99, 120, 126 f., 344 f.). According to Logical Investigations, the acts of intuitive presentation, the fact that I am seeing a certain house or that I am hearing the song of a nightingale, consist of the interpretation of the sensory contents present in consciousness as objects which appear, so as being the house in front of me or the song of the nightingale (LI, II, 341; see too $83 \mathrm{f}$., $103 \mathrm{ff} ., 109 \mathrm{f}$.). Although the sensory contents whereby such objects appear to consciousness are present in it or experienced, they are not intentional experiences or intentions. Rather they serve as bearers of certain interpretative act-characters of intentional acts, which interpret them in one way or another, as a house, the song of the nightingale, etc. (LI, II, 99, $104 \mathrm{f} ., 358$ ).

The Husserlian criticism of Brentano's conception of sensation is an extension of his disagreement with Brentano's conception on the structure of mental acts ${ }^{3}$ : for Brentano, any mental act is primarily directed toward the object and secondary toward itself. This last orientation is named by him inner perception and is also appropriate for sensations. In his $\mathrm{V}^{\text {th }}$ Logical Investigation Husserl maintains, however, that "the unbroken activity of inner perception cannot be phenomenologically demonstrated" (LI, II, 87; see too 98, 340). Once with the negation of this secondary direction of the act to itself, Husserl also denies, in the case of sensations, their primary direction toward an object and reduces them to their sensory contents.

In what follows I intend to offer a reading of the famous intentionality quote from Brentano's Psychology from an Empirical Standpoint (1874) that aims to prove that Brentano's analysis really faces a problem at the level of sensations. In a nutshell, this problem consists of the fact that the sensations are not characterized by a direction toward an immanent object, as Brentano implicitly maintains in the intentionality quote. In order to clarify this thesis from the start, I shall emphasize that I do not deny that for Brentano the act of sensation considered as a whole, i.e., together with its sensorial content, is directed to its physical cause considered as an extra-mental object. I accept this, but at the same time I consider the issue as having no relevance for the problem the intentionality passage attempts to solve, namely the distinction between mental and physical phenomena. As Brentano clearly points out, both of these phenomena are immanent to consciousness (PES, 88 f., 97 f., 181, 197; see also Simons 1995, XVII and Smith 1996, 42 ff.). For this reason, the distinction he is trying to establish refers to phenomena in consciousness, and not to the distinction between the immanent content of consciousness, on the one hand, and the extra-mental object the immanent content refers to,

\footnotetext{
${ }^{3}$ [For an argument on this issue, see Aldea 2014.]
} 
on the other hand. My [245] thesis is therefore the following: there is no orientation or direction of sensation as mental act toward its immanent object considered as phenomenal content of consciousness. ${ }^{4}$ This issue should be kept apart from the problem of the reference of the mental act of sensation to the physical cause whose action on the sense organ gives rise to its apparition in consciousness. At a more general level, the issue of intentionality as a matter of distinction between mental and physical phenomena should be distinguished from the issue of intentionality as a matter of how consciousness refers to extra-mental objects, either existent or non-existent. ${ }^{5}$

Obviously, one could consider the demonstration of this thesis as an additional argument in favour of Husserl's position that sensations are not acts. As far as I am concerned, I prefer to interpret this thesis as an expression of a disagreement between the two authors on the intentional relation and, generally, on the mental act. According to the interpretation proposed below, for Brentano, the intentional relations of presentation is fundamentally characterized by the fact that the mental act contains its object, and not by its orientation toward it.

[As is well known, intentionality provides grounds for philosophical pluralism (Moran 1996). In this respect, there are at least two ways of approaching the intentionality of sensation: the approach of analytic philosophy concerned with the investigation of intentional phenomena through the logical features of sentences wherein those phenomena are described (Chisholm 1967, 1989), and the traditional psychological approach that addresses the issue within Brentano's framework and also in Husserl's framework from the analyses devoted to Brentano in his Logical Investigations. The last approach does not deal with the features of intentional language, but with the features of mental acts as Brentano sets them forth in his empirical psychology. Unlike the first approach that led to an extensive research of Brentano's late thought, the account that I intend to give in this study leads to an examination of his early work, particularly of his early taxonomy of sciences and of the relation between this taxonomy and the program of Brentano's psychology.] For this reason, in the last parts of the study, I shall analyze the consequences of the thesis on the lack of direction of sensation toward its immanent object in Brentano's taxonomy of mental phenomena (second section), and in his early taxonomy of the philosophical sciences (third section). For these purpose, I shall distinguish two concepts of mental phenomenon, one in a narrow sense, another in a

\footnotetext{
${ }^{4}$ In what follows, I shall use the phrases 'physical phenomenon' and 'phenomenal content of consciousness' as different names for the immanent object of sensation, and I shall consider it as mind-dependent. For a different approach of this issue, see Ryckerson (2007, $38 \mathrm{f}$.), and the note 28 below.

${ }^{5}$ See on this issue Tănăsescu 2015a
} 
broad sense, and shall later analyse the meaning of this distinction from the perspective of the program of Brentanian empirical psychology. As we know, one of the fundamental tasks of this program is that of establishing psychology as an empirical science through the separation of its research domain, the world of mental phenomena, from the research domain of the science of nature, the world of physical phenomena (PES, 44, $50 \mathrm{f}$., $88 \mathrm{f}$., $98 \mathrm{ff}$.). Another important objective of this program consists of the separation of the main classes of mental phenomena precisely on the basis of the features enumerated in the intentionality quote. As a consequence, the goal of this quote in the 1874 work was not so much that of offering a theory about the way in which consciousness relates to non-existent objects, ${ }^{6}$ but that of contributing to achieving two major tasks of empirical psychology as a science: the separation of its research domain from the research domain of the sciences of nature and, further on, that of ordering the phenomenal material of the thus decoupled research domain through the separation of the main classes of mental phenomena constituting it. In the third part of the paper I shall analyse the meaning of the above theses and of the program of Brentano's empirical [246] psychology from the perspective of his early classification of philosophical sciences and of his program for building an empirical, non-speculative philosophy.

\section{The Problem of the Intentionality of Sensation in the Psychology from an Empirical Standpoint}

Pages 88 f. from Franz Brentano's Psychology from an Empirical Standpoint are the classical locus of current theories of intentionality. It is here that Brentano reintroduced the problem of intentionality in contemporary philosophy, by saying:

"Every mental phenomenon is characterized by what the Scholastics of the Middle Ages called the intentional (or mental) inexistence of an object, and what we might call, though not wholly unambiguously, relation to a content, direction toward an object (which is not to be understood here as meaning a thing), or immanent objectivity. Every mental phenomenon includes something as object within itself. In presentation something is presented, in

\footnotetext{
${ }^{6}$ See for this purpose the critical remarks of Tim Crane about this reading grid (Crane 2006, $21 \mathrm{ff}$.). I specify at the same time that the thesis presented here about the meaning of the intentionality quote from the perspective of the program of Brentano's psychology goes into an entirely different direction than Crane's analysis.
} 
judgement something is affirmed or denied, in love loved, in hate hated, in desire desired and so on. This intentional inexistence is characteristic exclusively of mental phenomena. No physical phenomenon exhibits anything like it. We can, therefore, define mental phenomena by saying that they are those phenomena, which contain an object intentionally within themselves." 7 (PES, 88 f.; translation modified)

According to the universal quantifier present at the beginning of this quote, Brentano considers that the aforementioned features apply to all classes of mental phenomena: presentations, judgments and emotional phenomena. ${ }^{8}$ However, as I have already suggested, the thesis of this study is that the characterisation of mental phenomena from the intentionality quote is not as general as Brentano thought it to be, because it does not apply to an extremely important sub-class of mental phenomena, namely the sub-class of sensations.

For Brentano, sensations are those mental phenomena characterised by the fact that they contain a certain physical quality that only is present to consciousness, ${ }^{9}$ without the latter

\footnotetext{
${ }^{7}$ [A discussion on the distinction between mental and physical phenomena from the viewpoint of contemporary philosophy of mind can be found in Tassone (2011, $109 \mathrm{f}, 279)$.]

${ }^{8}$ The three classes constitute different modes of existence of the object in consciousness or different modes of the relation to a content (PES, 197). This shows from the very beginning that Brentano's classification of the mental states is based on two of the characteristics listed in the intentionality quote (see infra, section 2).

${ }^{9}$ [In the opening of his psychology, Brentano distinguishes two accounts of psychology as science: the traditional account that addresses psychology as science of the soul, and the modern account that addresses psychology as science of mental phenomena. For pragmatic reasons, because the latter account simplifies the work of the psychologist, since it is dependent on fewer assumptions than the former, it is the very approach preferred for analysing his 1874 work (see, in this respect, his statements on phenomenal psychology in PES, 14, 72). According to this approach, the content of sensation is no longer conceived, as it was the case in The psychology of Aristotle, in particular his doctrine of the active intellect (1867), as an Aristotelian sensory form, but as a physical phenomenon in the sense of modern natural science. In this respect, we could say that the notes to the intentionality quote that were meant to clarify the sense of his terminology do not fit the modern approach that he has chosen for drawing up his psychology (PES, 88). The reason for this incongruity is that those notes abound with references to the Aristotelian-scholastic tradition, without any reference to modern authors. In this respect, they could be considered as an extension of the issues addressed in The psychology of Aristotle. Nevertheless, the general, methodological framework of PES is not a traditional, Aristotelian-scholastic one, but a modern one (Volpi 1989): although Brentano illustrates the meaning of intentional inexistence by recourse to sources of the Aristotelian-scholastic tradition, what is actually immanent to the act of sensation is no longer the Aristotelian form, but the physical phenomenon in its modern sense (PES, 100). In Aristotle's account, senses are not wrong about their object, and forms exist both in things, in relation to matter, and independently of it, objectively in the soul (De an. II, 418a11-13, 424a, 17-20; Brentano 1977, 57, 54 f.). The modern account instead, emphasizes the fallible character of outer perception, and also the fact that what is given in the senses does not exist as such in the real world, and that between the contents of our sensations and the physical objects whose action on our sense organs yields their occurrence there are solely highly general spatial-temporal analogies (PES, 9 f., 19, 98 ff.). The differences between those two accounts of psychology highlighted above are major, significant ones, and cannot be overlooked. This is the reason why I think that, when approaching the issue of the Aristotelian character of PES, we should not extend it to the whole work, and we should also distinguish between the modern (as shown in the first book) general, methodological framework of PES and the content issues addressed in the second book (see Münch 1989). Brentano was highly influenced by the Aristotelian tradition in his approach to these last issues - we are referring to the core issue of distinguishing between mental and physical phenomena and classifying mental phenomena based on the note on intentional
} 
taking any attitude toward it, without considering it, for instance, as existent or non-existent, as is the case of the judgments of outer perception. According to these judgements, the sensory content of our sensible acts exists in a real way, independently of its perception (PES, 9 f., 19, 81, 98 ff., 198). In the 1874 work, Brentano gives as examples of sensations "hearing a sound, seeing a colored object, feeling warmth or cold". The sensory qualities or phenomenal contents corresponding to them are: "a color ... which I see, a chord which I hear, warmth, cold, odor which I sense;" (PES, 79 f.) Although the words 'color', 'chord', 'warmth' etc., could be understood both as [247] names for extra-mental proprieties of things and for the corresponding sensory contents, in the intentionality quote they are conceived in the latter sense, i.e., as names for the contents or immanent objects of consciousness. Therefore, the relation to a content specific to mental phenomena highlighted in this passage is primarily the relation to its immanent objects. ${ }^{10}$ In my opinion, this concentration or limitation of the approach to mental acts as the relation to immanent objects, and not to extramental objects, is not accidental in the 1874 work, but necessary, for only on the grounds of this limitation could Brentano achieve one of the main goals of his empirical psychology and, at the same time, of his foundation of an empirical, non-speculative philosophy, i.e., defining the research domains of mental science and of natural science. As I shall show in the last part of my paper, the fact that the mental act of sensation is characterized by a relation to the immanent object which is not a direction toward it is fully compatible with this reading of the intentionality passage concerned with the issue of distinguishing the two classes of phenomena, and not with the issue of their relation to extra-mental objects. I shall argue below that, with respect to sensation, this relation is not the same as the direction toward an object. It is also important to underline in this context that in the 1874 work the content of sensation is analysed in a double perspective: qua immanent object to the act of sensation, as is the case with the intentionality quote, and, on the other hand, in correlation to the physical cause that acts on the sense organ and produces the appearance of the sensory quality in consciousness. ${ }^{11}$

inexistence. (On the traditional account of the intentionality issue in Brentano see the ground breaking papers of Hedwig 1978-79, 1992, 2015b; see also Albertazzi 2006, Sauer 2006, Antonelli 2012 and Tănăsescu 2012).]

${ }^{10}$ The intentionality quote refers very clearly to the relation with a content or to the immanent objectivity of the mental act; see also DP where Brentano explicitly holds: "The realities which fall into our perception are psychical, i.e. they display an intentional relation, a relation to an immanent object." (DP, 139)

${ }_{11}$ The sensory qualities are signs of the physical causes they symbolise (PES, 19, $98 \mathrm{ff}$.). This distinction deserves to be noted because it constitutes one of the main differences of the way in which the content of sensation is approached in the 1874 work in comparison to the lectures on descriptive psychology later held by Brentano at the University of Vienna. In these lectures, the content of sensation is exclusively approached in connection to the mental act it belongs to (DP, 111-129). 
Unlike the physiological research from his time, which did not define the sensation through the intentionality note, Brentano took a step further and considered it as a mental phenomenon in the sense of the intentionality quote. According to the general definition from this quote, a sensation is defined

(a) By the intentional inexistence of an object, i.e., by the existence or presence of a sensory quality in consciousness,

(b) By the relation to a content, i.e., by the fact that every sensory act intentionally contains as immanent object a phenomenal content or a certain sensory quality (the seen colour, the heard sound, etc.),

(c) And also by a 'direction toward an object', where by an 'object' is to be understood the immanent object (PES, $88 \mathrm{f}$.).

For any sensation it is clear that the intentional inexistence of its object consists of the presence of the sensory content in consciousness. If we see things from the perspective of the sensory act, this presence can be described by means of [248] the expression 'relation to a content': the sensation includes or contains in an improper way, phenomenally or intentionally, precisely the sensory quality the sensation of which it is. But what does its direction toward the object, more precisely toward its immanent object, consist of? In other words, what does the direction of the sensation toward the sensory quality it contains consist of?

If I see a red spot on the horizon, then, according to the way Brentano describes things, in my consciousness a sensory quality of a certain type will be present, namely the red seen which is considered in the outer perception as a red of a really existing physical object (PES, 81, 198; DP, $17 \mathrm{ff}$.). The red seen is the phenomenal content or the immanent object of the sensation in which it is contained. The mental act of the sensation of red has to be distinguished from the phenomenal red that it contains, since Brentano describes the phenomenon of consciousness, the fact that I am conscious of my own mental acts, by saying that any mental state is primarily related to its immanent object and simultaneously and secondary upon itself (PES, 126-130). The act of seeing a red spot is characterized thus both by the relation of the intentional containing of the red seen as content of consciousness and, at the same time, by the relation to itself: I am seeing a red spot and I am aware of the fact that I see it. At this point of the analysis it is not important to offer a description in terms of the natural science of the red spot I see; consequently, it is not important that what I name a 'red spot on the horizon' is in fact a source of light far away, emitting ray beams on a certain 
wavelength (PES, 47). The fact that concerns us is that the effect of the action of these rays on the eye is the presence of a certain sensory quality in consciousness and that, due to this quality, I see the source of light as a red spot on the horizon. In his empirical Psychology, Brentano describes this presence in a different way: the intentional inexistence of an object, physical phenomenon, phenomenal and intentional existence, etc. (PES, 88, 92, $98 \mathrm{f}$.). At the same time, he distinguishes between the sensory quality and the mental act of the sensation containing it precisely because it is not the sensory quality, but the mental act of its sensation that is the bearer of the property of being secondarily related to itself, or of being self-aware. As we know, this secondary relation of the act with itself is named 'inner consciousness' by Brentano and is manifested in three modalities that are in agreement with his threefold classification of the mental phenomena: the self-presentation of the act, the evident judgement of the inner perception ( $I$ see a red spot), and the accompanying feeling belonging to the act (I feel pleasure or displeasure when I see the spot) (PES, Book II, Ch. 3). ${ }^{12}$

Fundamental to the problem discussed here is the evidence of inner perception constantly put by Brentano in opposition with the fallible character of outer perception (PES, 10, 91 f.). The evident - non-evident character of the two perceptions offers the foundation for the real, respectively the phenomenal, [249] intentional existence of the two classes of phenomena: just because inner consciousness is evident and is never wrong, Brentano considers that mental phenomena are real, in the sense that they exist as they appear or as they reveal themselves in perception or inner consciousness (PES, 91 f.; DP, 137 ff.). By contrast, just because over time much evidence has been gathered about the fallible character of outer perception, he considers it is better to assign to physical phenomena only a phenomenal and intentional existence (PES, 9 f., 92 ff.). ${ }^{13}$

Consequently, it is clear from everything mentioned above, that the intentional existence of the object of sensation consists of the fact that the sensory qualities are nothing but phenomenal contents of the mental acts. It is also clear that the relation to a certain content of the sensation consists precisely of the fact that it contains this quality. On the other

\footnotetext{
${ }^{12} \mathrm{I}$ am not entering here into the discussion of the problem of inner perception for Brentano; I am limiting myself only to the presentation of his main theses about this problem, to which he dedicates 3 chapters from the second book of his Psychology. I must also mention that in the 1911 edition of the chapters regarding the classification of the mental phenomena of 1874 , Brentano will doubt the fact that the secondary relation of the act with itself always contains within it a feeling: "Indeed, I believe the entire broad classes of visual and aural sensation to be completely free of affective character" (PES, 276; on this problem see Rutte 1897, Brandl 2011).

${ }^{13}$ Unlike the Aristotelian-scholastic tradition in which the intentional existence of the form in the soul is a reliable image of the real form, the intentional existence of the physical phenomena that Brentano talks about in his Psychology takes into account only their existence as contents of consciousness, thus their existence only as phenomena, and no guarantee of their real existence could be offered (PES, 9 f., 92 ff., 98 ff.).
} 
hand, it is not at all obvious what the direction toward an immanent object, characteristic according to the intentionality quote for every sensory act, consists of. From my point of view, there is no such direction toward the immanent object proper to the sensory act. If such a direction existed, it should, on the one hand, be different from the relation to a content of the sensation, thus from the fact that the sensation contains a certain phenomenal object or, seeing things from the perspective of this object, it should be different from the presence of its phenomenal content in consciousness. In Brentano's empirical psychology there is, however, no expression for designating this direction of the sensation. On the contrary, when he talks about sensations, and in general about presentations, Brentano describes them by permanently relating to their object, and not to a so-called direction of them. For this reason, the official thesis of Brentanian psychology with regard to sensations is the following: in sensation, in presentation in general, something only appears or is present in consciousness (PES, 81, 198).

However, if the (i) intentional relation of the sensation consists precisely in the inclusion of what appears as a physical phenomenon and if (ii) there is no direction of the sensation toward this phenomenon, which should be different from the fact that it contains its object, then (iii) it makes no sense to speak about a direction toward an immanent object at the level of the sensory act. However, such a direction pertains to the class of phenomena of judgement and to the class of the phenomena of love and hate, where it admits a positivenegative polarisation: I believe or I do not believe in the existence of a blue tree, I like or I do not like a dish, etc. ${ }^{14}$ Unlike these classes, the class of presentations is not characterized by such an opposition of the intentional relation, but only by an opposition of the presented object: I can present something white or something black, the number 3 or -3 , but I cannot present positively and negatively something white or black. Thus, the relation to an immanent object in the case of sensory presentations is not further differentiated [250] into a positive and a negative one, and this is a general feature of the class of presentations in relation with the other two classes grounded on it. ${ }^{15}$ For this reason, we can say that at the level of sensations (and of presentations, in general) we deal with a non-polar, monolithic relation to the object. My thesis is that this relation, at least in the case of sensations, is never directed toward its immanent object.

\footnotetext{
${ }^{14}$ Brentano 1969, 12 ff. For Brentano, any categorical judgment can be reduced to an existential judgement ("A is $\mathrm{B}$ ' to ' $\mathrm{AB}$ is') and the existential judgment is the basic form of the judgment (PES, 210-221).

${ }^{15} \mathrm{PES}, 10 \mathrm{f}$.
} 
This is the point where it becomes clear that Brentano works with another concept of intentional relation than Husserl. For Brentano the intentional relation of sensory presentation and of presentation in general consist in the improper, i.e., intentional containing of the object in the act. It is commonplace in specialist literature that in the background of this conception is the Aristotelian thesis on sensory knowledge. According to this conception, sensory cognition consists of taking on the form of the thing without its matter. ${ }^{16} \mathrm{By}$ 'the intentional inexistence of an object' Brentano describes exactly the result of this receiving, namely the immaterial presence of the form in the cognitive faculty. ${ }^{17}$

For Husserl, however, the relation of intentional containing plays no role in his analysis, because he establishes a new type of relationship between act and its contents than Brentano. At the basis of these relations lies the distinction between real and intentional contents of consciousness. The former (sensory contents, interpretative and assertive characters of the act) are present in consciousness as such, they are their real constituents. Husserl usually describes the relationship between them and consciousness saying that the former are experienced or given in the unity of consciousness (LI, II, $82 \mathrm{f}$.). As I said, the sensations belong for him to these real constituents of mind. On the other hand, the intentional contents are not included, as such, in consciousness, are not their real contents, but their intentional objects. These objects are meant by the fact that a real content of the act, its interpretative act-character (auffassender Aktcharacker) interprets in a certain way another real content of the act, its sensory content. It interprets, for example, certain spatial forms given in the consciousness as the home that I see or the sounds heard as the song of the nightingale (LI, II, 341, 358). In this sense Husserl says: "I find nothing more plain than the distinction here apparent between contents and acts, between perceptual contents in the sense of presentative sensations, and perceptual acts in the sense of interpretative intentions [...] One sees at once that the very same thing which, I relation to the intentional object, is called its presentation, [...] is also called an interpretation, conception, apperception in relation to the sensations really present in this act." (LI, II, $104 \mathrm{f}$.)

In summary, according to Husserl, the object is not an immanent object and the acts do not contain their objects, as they do for Brentano, but rather [251] the former means the latter. They do this by their intention as an act-character, which interprets the sensory content

\footnotetext{
${ }^{16}$ De an. II, 424a17-21, III, 431b30-432a1; on this problem, see Sorabji 1991, 226 f., 247 f., and Caston 1998, 249 f., 254 ff., $291 \mathrm{ff}$.

${ }^{17}$ In his habilitation thesis, Brentano already distinguishes between being materially contained in something, and being improperly, objectively (as a form or as an object in late scholastic terms) contained in the sense organ: "Materially, as physical quality, coldness is in the cold thing. As object, i.e., as something that is sensed, it is in him who fells the cold." (Brentano 1977, 210); see also PES, 88.
} 
in one way or another. Their orientation or direction toward the object is realised through this interpretation. As I have argued above, for Brentano, however, sensations are mental acts that lack the propriety of being directed toward their immanent object. There is no interpretative character of the act for him, but the act either contains its object (the sensory presentation and the presentation in general) or the act (the judgement or the affective phenomenon) accepts or rejects it.

In the following paragraphs I will take into account two elements that could claim to be the direction toward the immanent object of sensation. As I immediately show, this claim does not hold up to a critical exam.

(1) As we have already mentioned, for Brentano any mental phenomenon is characterized by a primary relation to the immanent object and by a secondary, threefold relation to itself: I see something and at the same time I present the fact that I see, I evidently judge that I see and feel in a certain way, pleasant or unpleasant, the fact that I see a red spot, for instance. This last opposition of the affective phenomena of inner consciousness could raise the claim to be the direction toward an object we are looking for. Nevertheless it cannot be considered as the direction toward the immanent object of sensation just because it belongs to the secondary relation of the act to itself, and not to its primary relation.

(2) The intentional relation specific for outer perception is another element of Brentano's psychology, which can be confused with the direction toward the immanent object of sensation. As is well known, for Brentano judgements of the outer perception express the belief, specific to common consciousness, in the real existence of phenomenal qualities: there is the seen green, the felt smell, the heard sound, etc. According to the explanations from Descriptive Psychology, this instinctive belief is opposed to the belief of the scientists who deny the real existence of these phenomenal qualities because they know that they only exist qua contents of consciousness (PES, 9 f., 91 ff.; DP, 92 ff.). Consequently, the relation of positive - negative opposition, specific for the intentional relation of the judgements and emotional phenomena, is present between the two judgements. However, this fact is not at all surprising, as the acts of perception are not presentations, but judgements, thus acts based upon presentations. As judgements, they express the belief in the existence or non-existence of the perceived object. But this intentional relation has to be distinguished from the intentional relation of sensory presentation: in sensation, something only appears or is present in consciousness, without the act of sensation believing in the existence or non-existence of the phenomenal quality that appears to it. This belief is specific for the perception founded on 
it. Due to the relation of foundation between the two, Brentano describes the perceived object as being twice in consciousness: first as presented object and then as object considered to be existent (PES, 201). Consequently, in Brentano's empirical Psychology, the outer perception has to be distinguished from sensation, just as the perceived object has to be distinguished from [252] the sensed object. ${ }^{18}$

At this point of the analysis, I must take into account a possible objection originating in the imprecision of the intentionality terminology employed by Brentano. According to this possible objection, we do not need to look for a direction of sensation toward its immanent object, because the relation of intentional containing of sensory presentation itself can be interpreted as a direction toward its immanent object: after all, the sensory intentional containing, the fact that, for instance, a certain sensation is exactly the sensation of this, and not that red, or that green, can very well be described by saying that the sensation is directed or oriented toward the red in question, and not toward another colour.

I respond to this objection by saying, first and foremost, that it confounds the relationship of intentional containing of the sensory act - the sensation intentionally contains its sensory quality - with the relationship of reference proprietary to its content: the fact that the sensation is a sensation of this content does not mean that the sensation is about this content or that it is oriented toward it. The sensation is not about its sensory contents, but is of the sensory contents and, thus, it is, because of their nature as signs, about the physical cause for which these signs stand. The sensation of red is not about the phenomenal red it

\footnotetext{
${ }^{18}$ In the 1874 work sensation is dealt with separately from perception that presupposes the consideration as existent of that which is felt; the relationship between them is described by the law of founding mental phenomena: because the judgments of outer perception consider as existent the object that appears, they are founded upon the sensation of the respective object (PES, 92 f., 209 f.). In Descriptive Psychology, Brentano already leans toward another position, one that does not consider outer perception as an act founded upon sensation anymore, but distinct from it; he holds that blind belief or the assertoric accepting in the sensed (seen, heard, etc.) object proper to outer perception is included in the fundamental act of the sensation (DP, 92 ff.). Things have not stopped here, however. Right after 1902, Brentano will give up for a short time the tripartite classification of mental phenomena, eliminating the class of presentations and considering that there exist only two fundamental classes of mental acts, judgements and emotional phenomena. One of the main arguments at the basis of this renunciation is constituted precisely by the fact that he did not interpret anymore (for instance, in his text from 1903 Von der Natur der Vorstellung) the indissociability of sensation from belief in the existence of the sensed object through the lens of the law of founding mental phenomena, but considered it as a sign of the fact that sensation is not a stand-alone act, but must be integrated in the perceptual act itself. For reasons as yet unclarified, Brentano will subsequently give up this idea and will tacitly come back to the tripartite classification of mental phenomena - in 1911, he republished the chapters about the classification of mental phenomena from his 1874 work, adding a large appendix keeping the classification from the 1874 work and presenting the most important changes occurring in his views in the meantime (see on this problem Brentano 1987a, 25-33, and Brandl's introduction to this text (Brandl 1987)).
} 
contains, but of the phenomenal red in question and, thus, about what the contained red symbolizes, about its physical cause, the source of light in question (PES, 19, 98 ff.). ${ }^{19}$

Secondly, this interpretation in an improper sense of the direction toward the object only makes the expression in question another name for the relationship of intentional containing proper to sensory presentation, a relationship also denoted by the expression 'relation to a content'. As a consequence, the two expressions would [253] become synonymous, and the price paid for this consists precisely of the fact that the terms 'direction', 'orientation' or 'aiming' toward something are used in an improper sense in order to designate what he also names the 'relation to a content', i.e., the fact that the act only contains its object, without thereby taking any attitude toward it, as is the case of judgements, for instance. In this way, however, we are still left with our problem, namely the absence of any element of the act of sensation that could be considered as a direction, orientation, or aiming of it toward an immanent object and that is distinct from the simple presence of its phenomenal content in consciousness. And if we accept the fact that the expression 'direction towards the object' indeed has this improper sense in Brentano - a fact undoubtedly supported by certain quotes from his Psychology, ${ }^{20}$ then one can rightly impute to Brentano that he multiplied entities beyond necessity. The ground of this objection is one that he introduced in his discourse on intentionality an expression, the 'direction towards an object', which, if used in an proper sense, does not apply to all mental phenomena and, if used in an improper sense, does not evince another aspect of mental phenomena beyond the one evinced by the expression 'relation to a content'.

\section{A Unitary Classification of Brentano's Mental Phenomena Can be Founded only on} the Expressions 'Intentional Inexistence of an Object' and 'Relation to a Content' Corresponding to it

\footnotetext{
${ }^{19}$ As said, the sensible qualities are signs of the physical causes the action of which over sense organs produce their appearance in consciousness. This distinction corresponds to the Husserlian distinction between the experienced sensory content, the content given in the unity of consciousness, and the properties of the perceived object evinced through them (LI, II, $82 \mathrm{f}$.).

${ }^{20}$ See the following quote where Brentano does not use the term Richtung (direction), but the verb corresponding to it: "Ferner haben wir gesehen, wie bei manchen Sinnesempfindungen das begleitende Gefühl von Lust und Unlust nicht bloss mit der Empfindung selbst, sondern sogar mit dem immanenten Gegenstande der Empfindung, mit dem physischen Phänomene verwechselt wurde, auf welches der Empfindungsact als auf sein primäres Object gerichtet ist." ("Furthermore we have seen above that in certain sensations the accompanying feeling of pleasure or displeasure has been confused not only with sensation itself, but even with the immanent object of sensation, i.e., with the physical phenomenon to which the act of sensation is referred as to its primary object." (My italics) PES, 112; see too PES, 158.)
} 
What is then the significance of the above-mentioned points for Brentano's view about mental phenomena and their classification? Do they mean, for instance, the fact that sensations should be excluded from the class of intentional acts, as Husserl proposes? (LI, II, II, 358). As I explained, for Brentano, any mental phenomenon, including sensation, is fundamentally defined by the conjunction between the primary relation to the immanent object and the secondary relation to itself. Although in the following I shall not continue to bring forward this relation, I ask the reader to have in mind the fact that any time I speak about the primary relation to the object I shall constantly assume that this relation is permanently accompanied by the secondary relation of the act with itself.

Approaching the problem of the primary relation to the immanent object, there are two possibilities for defining Brentano's intentionality. Consequently, there will be two possibilities for delimiting and distinguishing the class of the mental phenomena from the class of the physical phenomena. Preliminarily, I emphasise [254] that, from my point of view, the expressions 'intentional inexistence of an object' and 'the relation to a content' of the sensory act describe one and the same thing, the mental act, but from different perspectives: either from the perspective of the immanent object, or from the perspective of the intentional relation of the act. Hence, talking about the object that exists intentionally in the act means talking implicitly about the fact that the act contains intentionally the object and conversely. This fact does not at all mean neglecting the differences between the two: it is not the object, but the act that is self-aware, i.e., it is directed on a secondary level toward itself; it is not the object, but the mental act that exists in a real way in consciousness; its immanent object exists, on the other hand, only intentionally and phenomenally (PES, 91 ff.) In this context, the above said allows us to build two concepts of mental phenomena:

(1) The concept of mental phenomenon in a strict, narrow sense. According to this concept, any mental phenomenon is characterized by the intentional inexistence of the object, by the intentional containing of the object in the act and by the direction or orientation toward this object (PES, 88 f.). As we have seen, this concept places us in front of the following alternative, disadvantageous in each of its options: we either exclude the sub-class of sensations from the domain of mental phenomena, an unacceptable fact for Brentano, ${ }^{21}$ or we

\footnotetext{
${ }^{21}$ Although in Brentano's 1874 work he admits that the study of sensations represents a field in which the research of his empirical psychology intersects the research of Fechner's psychophysics, he has no doubts that the sensations are mental phenomena stricto sensu (PES, $6 \mathrm{ff}$., $98 \mathrm{ff}$.). This idea is in fact clearly confirmed by the following statement in Descriptive Psychology: "A sensation (Empfindung), I say, is a fundamental presentation of real physical phenomena (objects) [(Gegenstände)].” (Brentano 1982, 139; DP, 148, translation
} 
keep the sub-class of sensations. However, this comes at the price of giving up the proper sense of the term 'direction', that of orientation or aiming toward something, and to its consideration as a simple equivalent of the relation of intentional containing. This, however, transforms the narrow concept of mental phenomenon into a broad concept, as I shall present below.

(2) The mental phenomenon in a broad sense. According to this concept, any mental phenomenon is characterized by the intentional inexistence and by the relation of intentional containing of the object. Thus, we obtain a concept of mental phenomenon undetermined to a great extent, because it is formed on the basis of the notes proper to the class of presentations. In virtue of the law of founding mental phenomena, it is also applied to judgements and emotional acts; namely to the extent to which it applies to their foundation, the presentation, but without the ability to determine the specific character of their intentional relations.

The advantage of this concept is that it allows us to easily move the sensations in the domain of mental phenomena. Its disadvantage, however, is that it is imprecise, given that, interpreted in this general way, the two features apply to all the classes of mental phenomena which thus remain unseparated between them. [255]

From my point of view, this fact does not represent a major obstacle against defending a broad concept of the mental phenomenon, as the purpose of this concept is precisely that of differentiating the class of mental phenomena from that of physical phenomena, and not to further differentiate the fundamental classes of mental phenomena. The concept in discussion very well solves this problem, as it delimitates the mental world from the world of the physical phenomena exactly at their intersection, i.e., at the fundamental level of the sensory acts, for the study of which the approach of Brentano's psychology intersects the research of psychophysics and physiology (PES, 5 ff.). According to the hypothesis above, sensation is a mental phenomenon as it is different from its sensory content through the fact that it contains intentionally a certain sensory quality and it is selfaware. No physical phenomenon intentionally contains another immanent object and is selfaware.

In agreement with this hypothesis, there is no direction of the sensory act toward its immanent object. This means that the expression 'direction towards an object' must not be considered in order to separate the class of mental phenomena from that of physical ones because it is not a feature of any mental phenomenon. This also means that the features slightly modified). 
reunited under the broad concept of the mental phenomenon - the intentional inexistence of the object and its specific non-polar relation of intentional containing - are not sufficient for neither separating of the classes of judgment and emotional phenomena from the class of presentations, nor for the separating the first two classes between them. In order to achieve this, we need to take into account the differences between the intentional relation of the judgements and of the emotional phenomena.

But this is only the next step in the approach of establishing psychology as an empirical science, since it already assumes that the mental science was separated from the physical science through the differentiation of the basic classes of phenomena. As I have already shown, one of the main purposes of the intentionality quote is to contribute to the establishment of psychology as an empirical science by indicating the most relevant feature that separates the mental from the physical. For this reason, the intentionality quote only offers a characterisation of the mental phenomena as a genus, one that is accompanied by exemplifications at the level of all classes of mental phenomena. This characterisation is sufficient for the differentiation of the mental from the physical phenomena, and leaves open the question of their classification. Brentano treats this problem only in the last chapters of the second book of his Psychology, where the intentional inexistence of the immanent object and the intentional relation to a content are generally understood to represent the criteria for differentiating the classes of mental phenomena.

To sum up, if the intentional inexistence of the object and the relation to a content understood as a relation of intentional containing are sufficient for separating the mental from the physical, they are not longer sufficient for separating the main classes of mental phenomena. In other words, the two notes reunited in the broad concept of the mental phenomenon open the way to the research domain of psychology, the realm of mental phenomena, but without putting order into, and classifying, the elements making up this domain. For this purpose, we have to pay [256] attention to the way in which the intentional relation is differentiated into the relation to an object specific to presentation, judgment, and emotional phenomenon and to the types of inexistence of the object specific to them (the presented, judged, loved, or hated object). This shows us that the broad concept of the mental phenomenon is sufficient to separate the mental world from the physical world, while the narrow concept has the role of separating the phenomena of judging and emotional phenomena from both the class of presentations and between themselves. 


\section{The Intentionality of Sensation and Brentano's Early Taxonomy of Philosophical} Sciences

When Brentano characterized sensation through a relation to a content that consists in the fact that it contains its object, he did not mean that the ultimate object to which sensation relates is the immanent object. Generally speaking, the issue of defining the ultimate, final object that mental acts relate to is not one of the main issues in Psychology from an Empirical Standpoint. Moreover, regardless of how important it was for Brentano's students and, in the XXth century, for Chisholm to clarify how consciousness refers to extra-mental objects, either existent or non-existent, it should be said that this was not the problem Brentano was attempting to solve in the intentionality passage, and in his 1874 work. For this reason, the issue of determining the differences between physical and mental phenomena should not be approached from the outset from the standpoint of a theory on how consciousness refers to extra-mental objects. ${ }^{22}$ On the contrary, the "Introduction", the first book, and the first chapter of the second book of PES contain many clues that link the issue of determining the differences between the two classes of phenomena and the program of the 1874 work to both the issue of Brentano's early taxonomies of philosophical sciences, and his project for a positive philosophical science. Further, I shall argue in favour of this thesis.

As one of his early taxonomies of sciences drawn up in an introduction of his lectures on the history of philosophy at the Würzburg University shows, for Brentano philosophy is a natural, abstract science that divides into two disciplines: natural science and mental science, or philosophy in the narrow sense. ${ }^{23}$

\footnotetext{
${ }^{22}$ See, in this respect Husserl's LI and Chisholm 1967.

${ }^{23}$ ["I. Supernatural science; II. Natural science (one-sided independency): 1. Abstract science: 1) Mathematics, 2) Philosophy in a broad sense: a) Physical science, b) Mental science (philosophical science in a narrow sense); 2. Concrete science.” (Brentano, Ms. H 45: 'Gesch. d. Phil. Einteilung der Wissenschaften' (n. 25253); apud Hedwig (1987), XIII; about this problem, see Brentano (1869); Brentano (1893); Werle (1989); Hedwig (1987) and XXX). The distinction between supernatural science and natural science should be related to the fact that Brentano was a Catholic clergyman at that time. This distinction is also addressed in Brentano's second habilitation thesis: „Philosophy should object both to the claim of borrowing its principles from theology, and to the statement that only a supernatural revelation makes possible a fruitful philosophy." (Brentano 1866, 137). As $\mathrm{K}$. Hedwig has argued, the science from which Brentano distinguishes philosophy here is Thomas Aquinas' sacra doctrina. Hedwig has also indicated that this distinction has a transitory character, for in the M 96 manuscript theology is no longer distinct from philosophy, but it is integrated in it and becomes part of metaphysics (Hedwig 1987, XIII ff.; with respect to Brentano - Thomas - Aristotle relation, see also Hedwig 2012/2015).] Although I am not approaching here the issue of Brentano's taxonomy of sciences, it is worth noticing that in other of his early taxonomies he admits, among the two sciences already mentioned, metaphysics as a fundamental philosophical discipline (see, on this issue, Tiefensee's extensive analysis (Tiefensee 1998); for a concise and significant overview of Brentano's account of philosophy as science in the context of the $19^{\text {th }}$ century and on the significance of his work for contemporary philosophy, see Poli (1998), Albertazzi (2006 ch. 3) and also Tassone (2012).
} 
(1) If we correlate this taxonomy with his best known habilitation thesis: „The true method of philosophy is the method of natural science“ (Brentano 1929, 137); (2) if we understand this thesis in the sense that philosophy should approach its object in the same way natural science does, i.e., philosophy should draw its basic concepts from the experience of the phenomena that constitute its domain, not in an [257] idealistic, speculative fashion, from a principle; (3) if, finally, we consider Psychology from an Empirical Standpoint as actually grounded on this understanding of his habilitation thesis, then we could say that establishing an empirical psychology concerned with setting the features and the laws of mental phenomena constitutes one of the main ways for establishing an empirical, non-speculative philosophy (PES 5 f., 9 f.; see also Ms LS 22). Or, the first step in establishing a new science is defining its research domain against the research domains of other sciences, i.e., for psychology, defining its research field against the research field of natural science. This issue is transparent in the taxonomy of sciences displayed above, and it is present from the very beginning in the parts of the 1874 work mentioned above. ${ }^{24}$ In a fragment from the first part of this work, Brentano holds unequivocally:

"But the result of a more careful comparison and an analysis of all pertinent facts certainly seems to us to prove that much more information about physiological phenomena is to be expected from chemical phenomena than from physiological phenomena about mental phenomena. The difference between physiological processes and chemical and physical processes really seems to be only that physiological processes are more complex. [...] We can hardly say the same thing of the concept of life when we apply it to the physiological and psychical realms. On the contrary, if we turn our attention from the external world to the inner, we find ourselves, as it were, in a new realm. The phenomena are absolutely heterogeneous, and even analogies either forsake us completely or take on a very vague and artificial character. It was for this very reason that we separated the psychical and physical sciences as the main branches of empirical science in our earlier discussion of the fundamental divisions of that realm." (PES, $50 \mathrm{f}$.). ${ }^{25}$

\footnotetext{
${ }^{24}$ Contemporary exegesis pays no particular attention to the first book of PES that approaches mainly issues of method, focusing instead on the second part of the 1874 work, that may be well accounted for from the standpoint of contemporary philosophy of mind. Tassone $(2012,77-107)$ departs from this trend.

${ }^{25}$ Contemporary authors have repeatedly emphasized that Brentano took from Comte the idea of a range of phenomena based on their increasing complexity (see, for instance, Hickerson 2007, 26-31). The cited fragment shows that the idea is true with respect to relations between physical, chemical, and physiological phenomena. But with regard to mental phenomena, they do not constitute for Brentano a mere superior complication of physiological phenomena. On the contrary, they constitute an 'absolutely heterogeneous' realm, and their distinctive feature is the fact that they intentionally contain an object. The intentionality of the mental should
} 
If we further consider the first statement of the second book of Psychology from an Empirical Standpoint: "all the data of our consciousness are divided into two great classes the class of physical and the class of mental phenomena" (PES, 77), then we may notice that it not only serves to mark the delimitation of the two main classes of phenomena, whose features, among them intentionality, Brentano is analysing in the first chapter of this book. At the same time, it constitutes the actual solving of the taxonomic issue mentioned above, for it dissociates natural science and mental science by separating their research domains. Moreover, this separation [258] is also significant at another level, that of the foundation of an empirical, non-speculative philosophy, for through the delimitation of these two research fields, the way is open for establishing one of the main branches of philosophy as science, namely (empirical) psychology or, as it is called in the abovementioned taxonomy, philosophy in the narrow sense.

Finally, if we read in this classifying context the well-known conclusive statement at the end of the first chapter of the second book of his work: "the feature which best characterizes mental phenomena is undoubtedly their intentional inexistence" (PES, 98), then we should notice once again that by intentional inexistence Brentano does not intend, as today is widely accepted, to reintroduce in contemporary philosophy the issue of referring to non-existent objects, but (1) to separate the two classes of phenomena, (2) to separate the research domains of their corresponding sciences, and therefore (3) to make a major step toward establishing a scientific, non-speculative philosophy.

Originally, Brentano's intentionality thesis had also nothing to do with the issue of referring to non-existent objects (Chisholm 1967), but it had everything to do with his program of establishing an empirical psychology, of classifying philosophical disciplines, and of establishing an empirical philosophy. ${ }^{26}$ In other words, the distinction between

therefore not be conceived as a mere aspect of the superior complexity of mental phenomena, but as an aspect of their radical distinction with respect to the preceding phenomena in Comte's taxonomy of phenomena.

${ }^{26}$ [Chrudzimski's account (2001) constitutes a crucial contribution to clarifying the meaning that some of the key concepts of analytic philosophy acquire when they are employed in the analysis of Brentano's psychology, and also to approaching Brentano's theory of intentionality from the viewpoint of the issues addressed within the framework of contemporary analytic philosophy (see, for example, his subtle remarks on the meaning of Brentano's intentional relation (Chrudzimski 2001, $30 \mathrm{ff}$., 36, $48 \mathrm{f}$.)). However, the fact that his work does not take into account the methodological issues emphasized above, and is solely concerned with solving the problems arising from the failure of existential commitment and of the intersubstitutivity of the coextensive expressions salva veritate that Brentano's theory of intentionality has to face, makes it difficult to accept the outcomes of his account. It is not at all clear, for instance, that in PES the intended object of the mental act is the immanent object, and that the phrase 'direction toward an object' is synonymous with the phrase 'relation to a content'. With respect to the case of sensation highlighted above, it is obvious that Brentano conceives sensation from the start as a sign of the physical cause that acts upon the sense organs, and he does not mean that its immanent object, its sensory content is also its aimed object, as if we would see sensory contents instead of things (PES). On the contrary, the sensory content provides the relation of sensation to things, as is also the case 
physical and mental phenomena on the basis of intentional inexistence constitutes an essential moment in the foundation of both an empirical psychology and an empirical philosophy.

The analyses in the previous section on the lack of direction of sensation toward its immanent object become significant in this context, because the taxonomic standpoint involved in establishing an empirical psychology favours interpreting intentionality primarily as the relation of intentional containing of an object in consciousness, and not as orientation of consciousness to extra-mental objects. The reason is that the relation of intentional containing allows a clear distinction between the two classes of phenomena immanent to consciousness through assigning to each of them a different mode of being: mental phenomena really exist in consciousness, while physical phenomena only exist intentionally and phenomenally (PES, 92). On the contrary, based on the direction toward an object, this distinction can not be fully grasped, for if we consider it, as we do here, as direction toward the immanent object, then it does not apply to a main subclass of mental phenomena, namely to sensations. If we consider it as usual, i.e., as direction toward extra-mental objects, then the research exceeds the taxonomic framework of Brentano's psychology, for it no longer seeks to distinguish two classes of phenomena immanent to consciousness, but it raises the question of how consciousness refers to extra-mental objects. Or, this account of the issue is no longer concerned with separating phenomena, but requires considering the relation between immanent objects of the mental acts and extra-mental objects they refer to, and furthermore

with names, where significance as the immanent object of the nominal presentation act provides the relation of that act to the thing (see, in this respect, the fragments from the lectures on logic quoted by Chrudzimski (33f.)). Apart from how we decide to label this view - in the case of the fragments from the lectures on logic, the author refers to the theory of the two objects, the immanent object and the intended object targeted through it - it is important to grasp the common general structure of the act of sensation and of the nominal presentation: mental act (of sensation or of nominal presentation) - immanent object (sensory content or conceptual content) - and intended object or the object intuitively or abstractly presented through the immanent object. With respect to this structure, it is also important not to excessively multiply its explanatory models: Chrudzimski argues that in PES we deal with a theory of the object mainly defined by the fact that the intended object is the immanent object which is highly distinct from the theory of the two objects maintained in the lectures on logic (and also valid in the case of Brentano's late descriptive analysis of sensation, but not in his 1874 work (Chrudzimski 2001, $25 \mathrm{f}$., 34, 36, 131 f.)). However laborious his argument and charming the possibility to benefit from contemporary acquisitions when approaching Brentano's psychology, a more straightforward interpretation is to consider that in the 1874 work, for all the reasons we have highlighted above, Brentano focuses on the relation between the mental act and its immanent object, without explicitly addressing the relation between the immanent object and the intended object presented through it. Conversely, in his lectures on logic, the very nature of the topic under examination (the functions of a name) raises the issue of clarifying the relation between the immanent object (the significance of the name) and the way the act of presentation refers through this object to the intended object presented through it. In other words, the context of PES - the distinction between mental science and physical science through the distinction between their two corresponding classes of phenomena - is quite different from that of distinguishing the functions of a name in the lectures on logic. In the latter, clarifying the relation between the immanent object and the object presented through it is mandatory, while in the former, clarifying the distinction between two phenomena, the mental phenomenon and the physical phenomenon, both immanent to consciousness is mandatory. This is the reason why the relation to the extra-mental object becomes a secondary target.] 
clarifying the role of those objects in accomplishing the reference of mental acts to extramental objects. Therefore, the decisive question in the latter view is how do mental acts considered as a whole, i.e. together with their immanent objects, refer to extra-mental objects, and not which is the main distinctive difference between mental and physical phenomena. Furthermore, from the viewpoint of intentionality as a theory on referring to extra-mental objects, [259] immanent objects are not considered physical phenomena, as is the case in the chapter to which the intentionality passage belongs, but primarily as imaginary objects. ${ }^{27}$ The topic of the just mentioned chapter was, however, neither the distinction between immanent imaginary objects, such as Jupiter, and the mental phenomena whose content they are, nor the issue of how mental acts refer through those contents to the objects they present, but the differentiation of mental from physical phenomena.

The distinctiveness of this account becomes more evident if we point out and eliminate other accounts that may somehow be linked to the differentiation mentioned above:

Brentano's standpoint is not that of a natural scientist concerned with describing the physical phenomena through which the physical objects of the world act upon our sense organs. $^{28}$

Brentano's standpoint is neither that of a physiologist nor that of a genetic psychologist concerned with accounting for the genesis of sensation, for example with explaining the genesis of visual sensation by the fact that the light beams of a certain wavelength $(375-760 \mathrm{~nm})$ pass through the refractive (dioptric) media (cornea, aqueous humor, lens, etc.), affect the retina, and trigger nerve impulses that, through the optical nerves, are transmitted to the cortical area of the cerebral cortex responsible with the formation of the visual sensation (PES, 12).

In contrast, Brentano's viewpoint is that of a psychologist concerned with founding his science in relation to natural science and as distinct from it. This is the reason why Brentano takes into account only the outcome of the genetic process displayed above, i.e., the presence in consciousness of a certain sensory quality. This quality is regarded as a content of the mental act where it appears, and is approached from a counterintuitive standpoint, because Brentano has no further interest in analysing the relationship between the immanent

\footnotetext{
${ }^{27}$ Although from a different standpoint, Fréchette $(2012,114)$ has already argued that referring to imaginary objects (centaurs) does not constitute the paradigmatic case in approaching Brentano's intentionality. However, for accuracy, we should add that, despite the high significance that contemporary exegetics attaches to the imaginary objects issue in PES (Chisholm 1967), Brentano refers to them only once in his 1874 work (PES, 218 f.; cf., by contrast, the great number of references to the physical phenomenon issue (PES, 9 ff., 19, 60, 69 f., 83, 97 ff. et passim).

${ }^{28}$ This view still appears occasionally in the 1874 work (PES, 98 ff.).
} 
object and the extra-mental object, but he primarily attempts to establish the distinctive features of the physical phenomenon that distinguish it from the sensation whose immanent object it is. In other words, for emphasizing the distinctiveness of his account, we need to distinguish between the aforementioned direction of his analysis toward the 'inside' of the mental act and the epistemological view oriented towards the 'outside' and focused on establishing the cognitive value of the outcome of that process: the common man, for instance, takes the red color he sees as a real propriety of things, and thinks the external perception is not deceptive; but scientists and philosophers doubt it, and consider the red color as a sign of the action of certain forces of things [260]on the visual analyser (PES, $91 \mathrm{f}$; DP, 17, 92 ff.). ${ }^{29}$ It is also important to distinguish here between two paths of psychological analysis, one concerned with establishing psychology in relation to natural science and accounting for physical phenomena as content of sensations, and the other concerned with accounting for physical phenomena as content of the mental acts of imagination. Brentano's repeated insistence on distinguishing these paths and his statement that the investigation of physical phenomena of imagination is not the job of the natural scientist, but that of psychologist, are to be explained by the fact that his attempt to establish mental science in relation to natural science required a treatment of physical phenomena similar to that specific to natural science, i.e., as content of sensation that points to its physical cause (PES, $77 \mathrm{f}$., 98 f.). As he shows at the end of the first chapter of the second book of his Psychology natural science analyses physical phenomena with respect to the physical forces producing them and investigates "the laws of co-existence and succession" of these forces (PES, 99). As I have already suggested, in the 1874 work the psychology is built as science with constant reference to natural science.

Finally, we need to notice here that this view is remote from approaching the immanent object as imaginary object. Although frequently approached thus nowadays, this view has little in common with the original founding framework of PES. Moreover, because of this framework, PES does not provide sufficient data for clarifying how mental acts containing immanent objects such as imaginary beings or abstract concepts refer to extramental objects. ${ }^{30}$ Although the 1874 work does not specifically approach this issue, yet it

\footnotetext{
${ }^{29}$ Ryan Hickerson's sophisticated attempt to consider physical phenomena as physical forces that cause sensations, and appear in them as their content (Hickerson 2007, 22, 38 f., 42 f.) meets two objections: Brentano distinguishes them, and considers confounding them an error (PES, $98 \mathrm{f}$.); the intentional inexistence does not pertain to physical causes acting upon the sense organs and producing sensation, but to physical phenomena as content of sensations.

${ }^{30} \mathrm{I}$ am not going here into the details of an issue that I have addressed elsewhere (Tănăsescu 2015 b) I shall confine myself only to notice that in the lecture on logic from 1870 there are some very clear statements
} 
contains sufficient statements allowing its clarification: sensations refer to extra-mental objects, to their own physical causes through their sensory contents, for they are designed from the outset as signs of those objects (PES, 19). Therefore, sensation contains a sensory quality as its immanent object, and thereby, it relates from the start to the physical object its content refers to. Although sensation has no direction toward the immanent object, yet it is directed to extra-mental objects through its content. Therefore, the final object of sensation is not the immanent object, but the physical cause to which it points; Brentano's analysis is also by no means exposed to the idealistic danger of being closed in the realm of consciousness. On the contrary, from this standpoint we could argue that, despite their difference, PES implicitly continues the view of his habilitation treatise, namely the thesis that the contents of consciousness as [261] immanent objects refer to extra-mental objects (Brentano 1977, $54 \mathrm{f}$,, 58). Or, as I have already said, this is not the issue addressed in the intentionality passage and in the 1874 work, but the issue of distinguishing the two classes of phenomena and the sciences related to them. In this respect, the fact that mental phenomena of sensation are not characterized by a direction toward the immanent object is irrelevant, for essential to the distinction in question is not the direction toward the immanent object, but the fact that the mental act intentionally contains its object. This intentional containing is absolutely sufficient for the task of distinguishing between physical and mental phenomena.

What I have said above shows the importance of the status of physical phenomena in PES, because defining their specific features means establishing the features of that class of phenomena corresponding to the first section of the philosophical science, i.e., natural science. As seen above, the concrete realisation of the distinction between this science and mental science, i.e., the concrete separation and establishing of the two disciplines, constitutes in fact the very way philosophy actually becomes a science.

The distinction natural science - mental science also constitutes the framework for the foundation of empirical psychology, because in the 1874 work psychology and its research domain, mental phenomena, are approached from the beginning by reference to natural science and its research domain, physical phenomena. This is not the place of a thorough argument, but the specific relevance of this taxonomic framework for the particular organization of PES becomes clear if compared to the lectures on descriptive psychology.

showing that with respect to concepts, as well as sensations, mental act refers to extra-mental objects through the relation with immanent objects: "The name designates in a way the content of a presentation as such, that is, the immanent object; in another way it designates that which is presented by the content of a presentation. The former is the meaning of the name. The latter is what the name names. About this we say the name belongs to it. It is that which is the exterior object of the presentation, if it exists. We name things by means of the meaning." (EL 80.13.018) 
The main task of the latter is no longer distinguishing physical and mental phenomena in order to contribute to establishing psychology as science through reference to natural science. Rather, Brentano's lectures precisely aim at describing the life of consciousness through determining its ultimate elements and their relations (DP, 3, 83). Unlike the 1874 work, where mental phenomena are addressed through constant reference to physical phenomena, in the lectures the former are addressed independently. On the other hand, physical phenomena are no longer addressed in respect to their physical causes, but strictly as immanent contents of mental acts. ${ }^{31}$ Accordingly, mental science is no longer addressed in the lectures with a constant reference to natural science in general, but it is divided from the very beginning into descriptive psychology and genetic psychology (DP, 3 ff.). For this reason, the research devoted in the 1874 work to the relation between physical phenomena and their causes does not pertain to the research field of descriptive psychology, but to that of the genetic psychology.

What I have said above shows just how much contemporary exegesis has neglected the original program of Brentano's empirical psychology. Within this program - the analysis of the traditional issues of the intentionality passage had very well emphasized that fact intentionality does not mean direction toward an object, as is the case for Husserl, rather it means intentional immanence of the object in consciousness. The apparently very uncommon idea that, for Brentano, not all mental phenomena are defined through their direction toward an object only emphasizes the fact that, starting with Husserl, intentionality is addressed almost exclusively as direction toward extra-mental objects, and commentators are so used [262] to it that they are no longer able to grasp the original theoretical framework of Brentano's intentionality. The prevailing approach to Brentano's intentionality as such a direction tacitly replaces the theoretical framework specific to his empirical psychology and to his early program of establishing a non-speculative philosophy with the theoretical framework and the specific focuses of contemporary philosophy. Therefore, the change of perspective on Brentano's intentionality from a theory of direction toward extra-mental objects to a theory of the differences between physical and mental phenomena aiming at contributing to the foundation of an empirical philosophy is not widely understood nowadays.

In conclusion, I wish to notice that, beyond his significant contribution to the issue of intentionality, Franz Brentano is also appreciated nowadays for his commitment to an empirical, non-speculatively oriented philosophy (Haller 1988, Mezei and Smith 1998,

\footnotetext{
31 This approach is also maintained in Brentano's Untersuchungen zur Sinnespsychologie (1907).
} 
Niveleau 2014). If what I have said above is right, then his contributions in these two areas should not be approached separately, but together, for intentionality of mental phenomena does not constitute for him only a main feature of consciousness, but also an important step in addressing the question of the classification of sciences and the foundation of both psychology and philosophy as scientific disciplines. Therefore, approaching Brentano's intentionality from the viewpoint of how consciousness refers to extra-mental objects, either existent or non-existent, proves to be, despite its venerable tradition, a possible context of interpretation, but surely not Brentano's original intention. ${ }^{32}$

${ }^{32}$ For linguistic corrections and specialized comments, I am particularly indebted to Susan Krantz Gabriel. The paper is dedicated to the memory of Marius Dumitru. 


\section{References}

Albertazzi L (2006), Immanent Realism. An Introduction to Brentano. Springer, Dordrecht

[Aldea A S (2014) Husserl's Break from Brentano Reconsidered: Abstraction and the Structure of Consciousness. Axiomathes 24, pp. 395-426]

Antonelli M (2001) Seiendes, Bewußtsein, Intentionalität im Frühwerk von Franz Brentano. Karl Alber, Freiburg/München

Antonelli M (2012) Franz Brentano's Intentionality Thesis. In: Salice A (ed.) Intentionality. Historical and Systematic Perspectives. Philosophia, München, pp. 109-144

Aristotle (1995) The Complete Works of Aristotle (2 vol.). The Revised Oxford Translation (Bollingen Series LXXI 2). J. Barnes (ed.). Princeton, Princeton UP

Brandl J (1987) Vorwort zu F. Brentanos 'Von der Natur der Vorstellung'. Conceptus. Zeitschrift für Philosophie 53/54, pp. 19-25

Brandl J (2011) What is Pre-reflective Self-Awareness? Brentano's Theory of Inner Consciousness Reconsidered. Revue roumaine de philosophie 55, pp. 41-63

Brentano F Ms. H 45: Gesch. d. Phil. Einteilung der Wissenschaften

Brentano F Ms LS 22. In Antonelli (2001), pp. 451-452

Brentano F Ms EL 80: Logik (Spring 2011 edition). Rollinger, R. (ed.) URL = $<$ http://gandalf.uib.no/Brentano/texts/el/logik/norm/>

Brentano F (1866) Die 25 Habilitationsthesen (lateinisch und deutsch). In Brentano 1929, pp. 133-141

Brentano F (1867) Die Psychologie des Aristoteles, insbesondere seine Lehre vom Nous Poietikos; reprint 1967,

Wissenschaftliche Buchgesellschaft, Darmstadt

[Brentano F (1869) Auguste Comte und die positive Philosophie. In Brentano 1926, pp. 99-133]

Brentano F (1874) Psychologie vom empirischen Standpunkte. Duncker \& Humblot, Leipizig

Brentano F (1893) Über die Zukunft der Philosophie. In Brentano 1929, pp. 1-81

Brentano F (1907) Untersuchungen zur Sinnespsychologie. Duncker \& Humblot, Leipizig [263]

Brentano F (1929) Die vier Phasen der Philosophie. Kraus O (ed.), Meiner, Leipzig

Brentano F (1929) Über die Zukunft der Philosophie. Kraus O (ed.), Meiner, Leipzig

Brentano F (1969) The Origin of the Knowledge of Right and Wrong. Chisholm R M, Schneewind E H (eds.)

Hague C, Constable A (trans.), Routledge, London

[Brentano F (1977) The psychology of Aristotle, in particular his doctrine of the active intellect. George R (trans.), University of California Press, Berkeley]

Brentano F (1982) Deskriptive Psychologie. Chisholm R M and Baumgartner W (eds.), Meiner, Hamburg Brentano F (1987a) Von der Natur der Vorstellung. Conceptus. Zeitschrift für Philosophie 53/54, pp. 25-33

Brentano F (1987b) Geschichte der Philosophie der Neuzeit. Hedwig K (ed.), Meiner, Hamburg

Brentano F (1995a) Psychology from an Empirical Standpoint. Kraus O, McAlister L (eds.), Rancurello A C et al. (trans.), Routledge, London

Brentano F (1995b) Descriptive Psychology. Müller B (ed. and trans.), Routledge, London Caston V (1998) Aristotle and the Problem of Intentionality. Philos Phenomen Res LVIII/1998, pp. 249-298

Chisholm R M (1967) Brentano on Descriptive Psychology and the Intentional. In: Lee E N, Mandelbaum M H 
(eds.) Phenomenology and Existentialism. Hopkins, Baltimore, pp. 1-23

Chisholm R M (1989) The Objects of Sensation : A Brentano Study. Topoi 8, pp. 3-8

Crane T. (2006) Brentano's concept of intentional inexistence. In: Textor M. (ed.) The Austrian Contribution to

Analytic Philosophy. Routledge, London, pp. 20-36

Fréchette G (2012) Deux concepts d'intentionnalité dans la Psychologie de Brentano. In: Tănăsescu I (ed.) Franz

Brentano's Metaphysics and Psychology. Upon the Sesquicentennial of Franz Brentano's Dissertation. Zeta

Books, Bucharest, pp. 310-344

Haller R (1988) Franz Brentano ein Philosoph des Empirismus. Brentano Studien 1, pp. 19-30

Hedwig K (1978-79) Intention: Outlines for the History of a Phenomenological Concept. Philos Phenomen Res 39,

pp. 326-340

Hedwig K (1987) Vorwort. In Brentano F (1987b), pp. IX-XXXIX

[Hedwig K (1992) Über die moderne Rezeption der Intentionalität Thomas-Ockham-Brentano. In Follon J,

McEvoy J (eds.) Finalité et intentionalité: doctrine thomiste et perspectives modernes. Paris/Leuve,n

Vrin/Peeters, pp. 211- 235

Hedwig K (2012) ',... eine gewisse kongeniale Denkweise“. Brentanos Rückgriffe auf Thomas von Aquin in seiner

Dissertation'. In: Tănăsescu I (ed.) Franz Brentano's Metaphysics and Psychology. pp. 95-131; republished

in: Hedwig K (2015a), Circa Particularia. Studien zu Thomas von Aquin, Gerwing M (ed.). Regensburg,

Friedrich Pustet, pp. 321-346

Hedwig K (2015b), „eine wesentliche Umbildung”. Über die Transformation der Intentionalität bei Brentano“.

Brentano Studien, 13, pp. 121 - 151]

Hickerson R (2007) The History of Intentionality. Continuum International Publishing Group, London/New York

Husserl E (2001) Logical Investigations (2. vol.), Morand D (ed.), Findlay J N (trans.), Routledge, London

Jacquette D (2004) Brentano's concept of intentionality. In: Jaquette D (ed.) The Cambridge Companion to Brentano, Cambridge University Press, Cambridge, pp. 98-131

Moran D (1996) A case for philosophical pluralism: the problem of intentionality. In Archard D. (ed.) Philosophy and pluralism. Cambridge University Press, Cambridge, pp. 19-32

Mezei B M, Smith B (1998) The Four Phases of Philosophy. With an Appendix: The Four Phases of Philosophy and Its Current State by Franz Brentano. Rodopi, Amsterdam

Niveleau C-E (ed.) (2014) Vers une philosophie scientifique. Le programme de Brentano. Demopolis, Paris

Poli R (1998) The Brentano Puzzle: An Introduction. In: Poli R (ed.) The Brentano Puzzle, Ashgate, Vermont, pp. $1-13$

Rutte H (1987) On the Problem of Inner Perception. Topoi 6, pp. 19-25

Sauer W (2006) Die Einheit der Intentionalitätskonzeption bei Brentano. Grazer Philosophische Studien 73, pp. $1-26$

Simons P (1995) Introduction to the second edition. In Brentano (1995a), pp. XIII-XXIII

Smith B (1994) Austrian Philosophy. The Legacy of Brentano. Open Court, Chicago-La Salle

Sorabji R (1991) From Aristotle to Brentano: The Development of the Concept of Intentionality. In: Blumenthal H J and Robinson H M (eds.) Aristotle and the Later Tradition. Oxford Studies in Ancient Philosophy, Supp. 9. Oxford University Press, Oxford, pp. 227-259 
Tassone B. G. (2012) From Psychology to Phenomenology. Franz Brentano's Psychology from an Empirical Standpoint and Contemporary Philosophy of Mind. Hampshire, New York, Palgrave Macmillan.

Tănăsescu I (2013) Relația de conţinere intențională şi problema intenționalității senzației la Franz

Brentano. Studii de istorie a filosofiei universale XXI:201-218

Tănăsescu I (2015a) The two Theories of Intentionality in Brentano and the Program of Psychology from an Empirical Standpoint. Brentano Studien 13, pp. 211-231

Tănăsescu I (2015b) The Problem of the Intentional Relation of Presentation in Brentano's Empirical Psychology. Tijdschrift voor Filosofie 77/2015, pp. 251-271

Tiefensee E (1998) Philosophie und Religion bei Franz Brentano. Franke, Tübingen und Basel

[Volpi F (1989) War Franz Brentano ein Aristoteliker? Zu Brentanos und Aristoteles` Auffassung der Psychologie als Wissenschaft. Brentano Studien 2, pp. 13-29

Werle J (1989) Franz Brentano und die Zukunft der Philosophie. Studien zur Wissenschaftsgeschichte und Wissenschaftssystematik im 19. Jahrhundert. Amsterdam/Atlanta, Rodopi] 